\title{
Circulating Plasma Epstein-Barr virus DNA Load During the Follow-up Periods Predicts Recurrence and Metastasis in Nasopharyngeal Carcinoma
}

Sha-sha He

Sun Yat-sen University First Affiliated Hospital

Yun-ying Yang

Sun Yat-sen University First Affiliated Hospital

Yan Wang

Sun Yat-sen University First Affiliated Hospital

Yu-feng Ren

Sun Yat-sen University First Affiliated Hospital

Cheng-tao Wang

Sun Yat-sen University First Affiliated Hospital

Mei-yan Zhu

Sun Yat-sen University First Affiliated Hospital

Li-xia Lu

Sun Yat-sen University First Affiliated Hospital

yong chen ( $\nabla$ chenyong@mail.sysu.edu.cn )

Sun Yat-sen University Cancer Center

\section{Research article}

Keywords: Nasopharyngeal carcinoma, Epstein-Barr virus DNA, dynamic, survival, recurrence, metastasis

Posted Date: July 8th, 2020

DOl: https://doi.org/10.21203/rs.3.rs-40402/v1

License: (c) (1) This work is licensed under a Creative Commons Attribution 4.0 International License.

Read Full License 


\section{Abstract}

PURPOSE Epstein Barr virus DNA (EBV DNA) load has been identified as a prognostic factor in nasopharyngeal carcinoma, while the dynamic changes in the long period have not been explored. In this study, we evaluated EBV DNA kinetics and its role in the survival. METHODS We conducted a retrospective review of 900 NPC patients. Plasma EBV DNA levels were measured at various time points after treatment. The correlations of EBV kinetics with recurrence and metastasis were analyzed. After stratifying patients according to the EBV results, survival was compared using Kaplan-Meier estimates. 12 and 24-month landmark analyses for OS data were performed according to the EBV groups. RESULTS Patients with post-EBV $<2,500$ copies/ $\mathrm{mL}$ achieved better survival than the higher ones. Furthermore, patients with continuously elevated EBV DNA had significantly poorer OS (HR: 2.542, 95\%Cl: $2.077-$ 3.111, P < 0.001), DMFS (HR: 2.970, 95\%Cl: 2.392-3.687, P < 0.001), LRFS (HR: 1.699, 95\%Cl: $1.072-$ $2.692, \mathrm{P}=0.013)$, and PFS (HR:2.535, 95\%Cl: $1.987-3.233, \mathrm{P}<0.001)$ than patients with continuously normal EBV or those with elevated levels at any time-point. The 5-year OS with elevated EBV was lower than the remission group by the 12 and 24-month landmark analysis. CONCLUSIONS Elevated EBV DNA after treatment was a better predictive indicator of survival than the baseline concentrations. Furthermore, continuously elevated EBV DNA after treatment indicated recurrence, metastasis and unfavorable prognosis for NPC. In addition, EBV DNA was predictable no matter how long the follow-up time.

\section{Introduction}

The incidence of nasopharyngeal carcinoma (NPC) has remained consistently high in endemic regions such as Southern China and Southeast Asia, with a peak incidence of 50 cases per 1,00,000 individuals $[1,2]$.

According to the National Comprehensive Cancer Network (NCCN) guidelines [3], radiotherapy is the primary treatment for NPC, combined with different chemotherapeutic strategies and sequential according to the disease staging. Concurrent chemoradiotherapy is the standard option for locoregionally advanced NPC. With the improved local control and survival resulting from more precise imaging and radiotherapy, recurrence and especially distant metastases have become the main cause of the failure of this mode of treatment [4].

Positive rescue treatment is necessary for locoregional recurrence and distant metastasis of NPC, and can achieve some level of curative success. In SYSUCC, treatment of 132 patients with recurrent NPC with intensity-modulated radiotherapy (IMRT) resulted in a 3-year local PFS and OS rates of $85.3 \%$ and $41.6 \%$, respectively [5]. Cervical residual lesions can be treated effectively by surgical resection. Improvements in chemotherapy and the application of targeted therapy for distant metastasis of NPC have greatly improved the efficacy of rescue treatment and further improved patients' survival [6].

Early diagnosis of recurrence and metastasis is the key to improving the efficacy of rescue treatment. For all patients, regular review is conducted every 4-6 months after 3-5 years of treatment and imaging is 
the main monitoring method. The scattered nature of recurrent tumor cells after radiotherapy renders biopsy unreliable for diagnosis, leading to a delay in rescue treatment of more than 10 weeks [7]. Fludeoxyglucose-positron emission tomography provides higher sensitivity and specificity for the diagnosis of recurrence and metastasis than computed tomography (CT) or magnetic resonance imaging (MRI), while the examination is expensive [8, 9]. Therefore, a sensitive, cost-effective and practical diagnostic index is required.

We have previously reported the potential benefits of adjuvant treatment for patients with detectable Epstein Barr virus DNA (EBV DNA) load at the end of treatment [10] in addition to the prognostic value of EBV DNA concentrations during treatment [11]. Tumor response and patient survival can also be predicted based on the clearance rates of plasma EBV DNA during the first month of chemotherapy. Therefore, early changes in the chemotherapy regimen may be considered for patients with a slow plasma EBV DNA clearance rate [12]. Furthermore, EBV DNA may be useful for identifying high-risk patients and guiding individual therapy in NPC. Moreover, since patients with recurrent and metastatic NPC have significantly higher EBV DNA than patients in clinical remission $(P<0.01)$, EBV DNA is implicated as a sensitive tumor marker for monitoring tumor recurrence and metastasis after radiotherapy in NPC [13-15].

The mechanism underlying the role of EBV DNA in NPC remains unclear and no risk classification has been effectively demonstrated; however, previous studies have focused on the dynamic changes in viral load during the follow-up. Thus, in this study, we hypothesized that the dynamic changes in plasma EBV DNA after treatment can be used to predict recurrence or metastasis of NPC. To better assess the correlation of survival with EBV DNA during the follow-up, we performed 12 and 24-month landmark analyses.

\section{Materials And Methods}

\section{Patients}

From January 2010 to September 2013, 900 consecutive patients who had confirmed diagnosis of nonmetastatic NPC and received radical radiotherapy in Sun Yat-Sen University Cancer Center (SYSUCC) were enrolled for initial screening. The selection criteria were as follows: (1) good performance status (KPS 280); (2) normal renal, cardiac and liver function; (3) complete EBV DNA record during treatment and 3 years after treatment; and (4) complete follow-up data.

\section{Treatments}

The therapeutic protocol was based strictly on the NCCN guidelines. All patients received the following treatment: stage I, IMRT alone; stage II, IMRT with concurrent chemotherapy; stage III and IVA-B, concurrent chemoradiotherapy with or without neoadjuvant or adjuvant chemotherapy. All patients underwent targeted radiotherapy using a thermoplastic mask based on CT simulation. Radiation Therapy Oncology Group guidelines were applied for target delineation. Planning target volume (PTV) was defined 
as the primary tumor (PTVp) and positive lymph node (PTVn), high-risk planning target volume (PTV-HR) was defined as the PTVp with an appropriate margin, and low-risk PTV (PTV-LR) was defined as PTV-HR with an appropriate margin plus the elective lymph node region. The treatment consisted of definitive radiotherapy with a total dose of 68-72 Gy to PTVp, 60-68 Gy to PTVn, 60-62 Gy to PTV-HR, and 5054 Gy to PTV-LR. Neoadjuvant or adjuvant chemotherapy consisted of cisplatin with 5-fluorouracil or cisplatin with taxanes, or all three together, administered tri-weekly for 2 or 3 cycles. Concurrent chemotherapy consisted of cisplatin/nedaplatin administered tri-weekly or weekly until the end of radiotherapy.

\section{Quantification of plasma EBV DNA}

DNA was extracted from plasma using the QIAmp DNA Blood Mini Kit (Qiagen, Germany) and EBV DNA was quantified using a RTQ-PCR system targeting the BamHI-W fragment region of the EBV genome and the 2. TaqMan reagent (Roche). Amplification was carried out using a LightCycler ${ }^{\circledR} 2.0$ Real-Time PCR system (Roche Applied Science). A plasma EBV DNA concentration of $<10^{3} \mathrm{copies} / \mathrm{mL}$ was defined as an undetectable.

\section{Follow-up}

The endpoints for this study were overall survival (OS), measured from the date of first NPC diagnosis to either the date of death or loss to follow-up; distant metastasis-free survival (DMFS, to distant relapse or patient censorship or death at last follow-up); locoregional-free survival (LRFS, to tumor relapse or patient censorship or death at last follow-up) and progression-free survival (PFS, to locoregional failure, distant failure or death from any cause, whichever occurred first). After treatment, patients were scheduled for regular follow-up visits every 3 months during the first 2 years, then every 6 months until the fifth year, and yearly thereafter. Evaluations during each out-patient visit included physical examination, hematology, and biochemistry profiles, MRI scan, chest radiography, abdominal sonography, and a wholebody bone scan. The surveillance work-up included EBV DNA load.

\section{Statistical analysis}

Statistical analysis was performed using IBM SPSS software version 22.0 (IBM Corp., Armonk, NY, USA). Survival outcomes were estimated using the Kaplan-Meier method and compared with the log-rank test. A univariate logistic regression model was used to examine the association between clinical factors, EBV status and survival outcomes. A multivariate Cox regression model and the chi-squared test were used to determine the correlation between plasma EBV DNA and treatment outcomes. Factors with a $P$-value of $\leq 0.05$ in the univariate analysis were entered into the multivariate Cox regression model. All tests were two-sided, and a $P$-value of $<0.05$ was considered statistically significant.

The inherent statistical weakness is guarantee-time bias. As recommended by statisticians, in this study, we investigated EBV NDA as a predictor of survival by performing time-dependent response analyses using Landmark and risk-of-death methods, thereby minimizing guarantee-time bias. 


\section{Ethics Statement}

The study was approved by the ethics committee of Sun Yat-sen University Cancer Center and the informed consent for collection and publication of medical information was obtained from all study patients at their first visit to our hospital.

\section{Results}

\section{Dynamic change patterns of EBV DNA}

A total of 900 NPC patients treated at SYSUCC between January 2010 and September 2013 were retrospectively enrolled. Median age was 44 years (range, $11-77$ years) and $99.6 \%$ of patients were male. All patients were non-keratinizing undifferentiated squamous cell carcinoma. According to the clinical examination during the follow-up (median 55.78 months), there were 21 cases of nasopharyngeal locoregional recurrence and 97 cases developed metastasis ( 25 cases of bone metastasis, 31 lung, 26 liver, 2 lymph node, 2 bone and lung, 2 liver and lung metastasis, 2 bone and liver, and 7 multiple sites). The baseline clinical features of the patients were shown in Table 1. 
Table 1

Summary of the clinical features of the 900 patients with NPC included in this study.

\begin{tabular}{|ll|}
\hline Characteristic & Total \\
\cline { 2 - 2 } & (No, \%) \\
\hline Age (years) & $900(100)$ \\
\hline$<44$ & \\
\hline$\geq 44$ & $461(51.2)$ \\
\hline Sex & $439(48.8)$ \\
\hline Male & \\
\hline Female & $897(99.7)$ \\
\hline Smoker & $3(0.3)$ \\
\hline Yes & \\
\hline No & $207(23.0)$ \\
\hline Overall stage (8th edition) & $693(77.0)$ \\
\hline I & $85(9.4)$ \\
\hline II & $231(25.7)$ \\
\hline III & $428(47.6)$ \\
\hline IVAB & $156(17.3)$ \\
\hline T category & $103(11.4)$ \\
\hline T1 & $43(4.8)$ \\
\hline T2 & $142(15.8)$ \\
\hline T3 & $427(47.4)$ \\
\hline T4 & $121(13.4)$ \\
\hline N category & \\
\hline N0 & \\
\hline N1 & \\
\hline N2 & \\
\hline
\end{tabular}




\begin{tabular}{|ll|}
\hline Characteristic & \multicolumn{1}{l|}{ Total } \\
\cline { 2 - 2 } & $\mathbf{( N o , \% )}$ \\
\hline Treatment & \\
\hline IMRT & $222(24.7)$ \\
\hline CT + IMRT & $678(75.3)$ \\
\hline Pre-EBV DNA (copies/mL) & \\
\hline$<4000$ & $473(52.6)$ \\
\hline$\geq 4000$ & $427(47.4)$ \\
\hline Post-EBV DNA (copies/mL) & \\
\hline$<2500$ & $774(86.0)$ \\
\hline$\geq 2500$ & $126(14.0)$ \\
\hline
\end{tabular}

At the end of treatment, $25.4 \%$ (229/900) of patients were EBV DNA-positive (median concentration 0 copies/mL; range 0-26,400,000 copies/mL). Pre-treatment, 72.0\% (648/900) of patients were EBV DNApositive (median concentration 3,205 copies/mL; range $0-49,100,000$ copies $/ \mathrm{mL}$ ). The post-treatment EBV DNA load was significantly lower than the pre-treatment concentrations $(P<0.01)$.

Patients were then divided into three groups according to the follow-up results. sustained remission consisted of 778 patients without recurrence or metastasis at the end of the follow-up, locoregional recurrence consisted of 21 patients with recurrence at any time-point and metastasis consisted of 97 patients with metastasis at any time-point.

After radiotherapy, 39.18\% (38/97) of the metastatic NPC patients were EBV DNA-positive (median 0 copies/mL; range $0-26,400,000$ copies $/ \mathrm{mL}$ ) and $33.33 \%(7 / 21)$ of the recurrent NPC patients were EBV DNA-positive (median 0 copies/ $\mathrm{mL}$; range 0-226,000 copies $/ \mathrm{mL}$ ). In the sustained remission group, $23.15 \%$ (181/782) of patients were EBV DNA-positive (median 0 copies $/ \mathrm{mL}$; range $0-843,000$ copies $/ \mathrm{mL}$ ). At the end of radiotherapy, the EBV DNA load of some patients in sustained remission were still EBV DNA-positive, although the number was significantly lower than that in the other two groups ( $P=$ $0.01)$, with no significant difference between the recurrence and metastasis groups $(P=0.562)$.

We then evaluated the dynamic changes in EBV DNA load at each point-time. At the end of therapy, the EBV DNA load decreased rapidly in the sustained remission and metastasis groups (median 0 copies $/ \mathrm{mL}$ ). Subsequently, there was no marked change of the EBV DNA load in sustained remission group ( $<4,000$ copies $/ \mathrm{mL}$ ), although the EBV DNA load in the metastasis group increased significantly ( $P$ $=0.025)$, reaching a peak at 3 months followed by a decrease to 1 year, and no marked change to 3 years $(<5,000$ copies $/ \mathrm{mL})$. The viral load in the recurrence group had increased rapidly by 3 months after treatment, and was lower than that in the metastasis group 1 year after treatment. This was followed by a 
gradual increase after 1 year, with a higher peak viral load in the recurrence group than that in the metastasis group, reaching 26,000 copies/mL at 12 months, 168,000 copies $/ \mathrm{mL}$ at 24 months, and 375,000 copies $/ \mathrm{mL}$ at 36 months, until the highest level at the time of relapse was $24,100,000 \mathrm{copies} / \mathrm{mL}$ (Fig. 1).

\section{Impact of EBV DNA levels on survival}

According to the ROC curve analysis, the pre- and post-treatment cutoff values for EBV DNA were 4,000 copies/mL and 2,500 copies/mL, respectively. The 5-year OS, DMFS, and PFS rates for the high and low pre-treatment EBV DNA levels were $83.6 \%$ and $90.0 \%, 84.1 \%$ and $92.9 \%$, and $87.6 \%$ and $94.1 \%$, respectively. These data suggested that elevated EBV DNA before treatment was associated with a poorer OS (HR:1.647, 95\%Cl: 1.126-2.408, $P=0.009$; Fig. 2A). Similarly, elevated EBV DNA before treatment also indicated significantly decreased DMFS compared with lower EBV (HR: $2.377,95 \% \mathrm{Cl}: 1.558-3.626, P<$ 0.001 ; Fig. 2B) and PFS (HR: 2.035, 95\%Cl:1.279-3.237, $P=0.003$; Fig. 2D), but not LRFS $(P=0.754$; Fig. 2C).

A total of 473 patients had pre-treatment EBV DNA loads below the cutoff value of $4,000 \mathrm{copies} / \mathrm{mL}$. Among them, 21 patients had post-treatment EBV DNA loads higher than 2,500 copies/mL, there were 18 cases with residual tumor, 32 developed metastasis, and 45 died.

A total of 427 patients had pre-treatment EBV DNA loads higher than 4,000 copies $/ \mathrm{mL}$. Among them, 369 patients had post-treatment EBV DNA loads below 2,500 copies/mL, 46 patients developed metastasis, eight had recurrence, and 41 died. Among the 58 of 427 patients with post-treatment EBV DNA higher than 2,500 copies/mL, 19 patients developed metastasis, 4 locoregional recurrence, and 22 died, with a higher proportion. Thus, these data indicated that post-treatment EBV DNA load had a much more marked influence on the prognosis of patients with NPC than pre-treatment EBV DNA load.

The patients were then divided into two groups according to the post-treatment EBV DNA cutoff values. The prognosis in the high post-treatment EBV DNA group was poorer than that of the lower EBV DNA group. Patients with post-treatment EBV DNA $<2,500 \mathrm{copies} / \mathrm{mL}$ achieved better OS $(P<0.001)$, DMFS $(P$ $=0.040)$, LRFS $(P=0.004)$, and PFS $(P=0.001)$ than patients with higher post-treatment EBV DNA.

Other risk factors, including smoking, advanced tumor stage, elevated CRP before treatment and therapy were correlated with poor OS, DMFS and PFS. Multivariate analysis was also performed, incorporating patient factors (age, sex, smoking), tumor factors (TNM stage), treatment methods (radiotherapy and chemotherapy) and post-treatment EBV DNA load as covariates. As shown in Table 2, post-treatment EBV DNA load was confirmed as an independent prognostic factor for OS (HR: $2.019,95 \% \mathrm{Cl}: 1.305-3.122, P$ $=0.002)$, DMFS (HR: $1.565,95 \% \mathrm{Cl}: 1.051-2.515, P=0.044)$, LRFS (HR: $5.363,95 \% \mathrm{Cl}: 2.201-7.312, P=$ 0.008 ) and PFS (HR: $1.940,95 \% \mathrm{Cl}: 1.153-3.264, P=0.013)$. According to these data, post-treatment EBV load has a great impact on survival and was identified as an independent prognostic factor for OS, DMFS, LRFS, and PFS. 
Table 2

Cox's proportional hazards regression model of OS, DMFS, LRFS and PFS

\begin{tabular}{|c|c|c|c|c|c|}
\hline & Variable & $\begin{array}{l}\text { Univariate analysis } \\
\text { HR (95\% Cl) }\end{array}$ & $P$ & \multicolumn{2}{|l|}{$\begin{array}{l}\text { Multivariate analysis } \\
\text { HR }(95 \% \mathrm{Cl}) P\end{array}$} \\
\hline & \multicolumn{5}{|l|}{$\begin{array}{l}\text { C-reactive protein } \\
(\mathrm{mg} / \mathrm{L})\end{array}$} \\
\hline & $\geq 1.655$ vs. $<1.655$ & $\begin{array}{l}1.796(1.217- \\
2.648)\end{array}$ & 0.003 & & \\
\hline & \multicolumn{5}{|l|}{ Platelet $\left(\cdot 10^{9} / \mathrm{L}\right)$} \\
\hline & $\geq 268$ vs. $<268$ & $\begin{array}{l}1.569 \\
2.315)\end{array}$ & 0.023 & & \\
\hline & \multicolumn{5}{|l|}{ T category } \\
\hline & T3-4 vs. T1-2 & $\begin{array}{l}1.429(1.165- \\
1.753)\end{array}$ & 0.001 & & \\
\hline \multirow[t]{13}{*}{ OS } & \multicolumn{5}{|l|}{$\mathrm{N}$ category } \\
\hline & N2-3 vs. N0-1 & $\begin{array}{l}2.343(1.873- \\
2.932)\end{array}$ & $<001$ & $\begin{array}{l}1.573(1.138- \\
2.175)\end{array}$ & 0.006 \\
\hline & \multicolumn{5}{|l|}{$\begin{array}{l}\text { Overall stage (8th } \\
\text { edition) }\end{array}$} \\
\hline & III + IV vs. I+ II & $\begin{array}{l}4.139(2.362- \\
7.253)\end{array}$ & $<.001$ & $\begin{array}{l}2.953(1.267- \\
6.886)\end{array}$ & 0.012 \\
\hline & \multicolumn{5}{|l|}{ Therapy } \\
\hline & IMRT + CT vs. IMRT & $\begin{array}{l}2.132(1.662- \\
2.736)\end{array}$ & 0.002 & & \\
\hline & \multicolumn{5}{|l|}{ Post-EBV (copies/ml) } \\
\hline & $\geq 2500$ vs. $<2500$ & $\begin{array}{l}2.333(1.519- \\
3.584)\end{array}$ & $\begin{array}{l}< \\
0.001\end{array}$ & $\begin{array}{l}2.019(1.305- \\
3.122)\end{array}$ & 0.002 \\
\hline & \multicolumn{5}{|l|}{ Smoker } \\
\hline & Yes vs. no & $\begin{array}{l}1.523(1.173- \\
2.340)\end{array}$ & 0.045 & & \\
\hline & \multicolumn{5}{|l|}{ T category } \\
\hline & T3-4 vs. T1-2 & $\begin{array}{l}1.365(1.103- \\
1.690)\end{array}$ & 0.004 & $\begin{array}{l}1.856(1.051- \\
3.279)\end{array}$ & 0.033 \\
\hline & \multicolumn{5}{|l|}{$\mathrm{N}$ category } \\
\hline DMFS & N2-3 vs. N0-1 & $\begin{array}{l}7.766(5.213- \\
11.570)\end{array}$ & $<.001$ & $\begin{array}{l}4.411(2.754- \\
7.065)\end{array}$ & $<.001$ \\
\hline
\end{tabular}




\begin{tabular}{|c|c|c|c|c|c|}
\hline & Variable & $\begin{array}{l}\text { Univariate analysis } \\
\mathrm{HR}(95 \% \mathrm{Cl})\end{array}$ & $P$ & \multicolumn{2}{|l|}{$\begin{array}{l}\text { Multivariate analysis } \\
\text { HR }(95 \% \mathrm{Cl}) P\end{array}$} \\
\hline & \multicolumn{5}{|l|}{$\begin{array}{l}\text { Overall stage (8th } \\
\text { edition) }\end{array}$} \\
\hline & III + IV vs. I+ II & $\begin{array}{l}5.918(2.981- \\
11.747)\end{array}$ & $<.001$ & $\begin{array}{l}5.792(2.303- \\
14.565)\end{array}$ & $\begin{array}{l}< \\
0.001\end{array}$ \\
\hline & \multicolumn{5}{|l|}{ Post-EBV (copies/mL) } \\
\hline & $\geq 2500$ vs. $<2500$ & $\begin{array}{l}1.619(1.010- \\
2.595)\end{array}$ & 0.040 & $\begin{array}{l}1.565(1.051- \\
2.515)\end{array}$ & 0.044 \\
\hline & \multicolumn{5}{|l|}{$\mathrm{N}$ category } \\
\hline & $\mathrm{N} 2-3$ vs. N0-1 & $\begin{array}{l}2.630(2.025- \\
3.417)\end{array}$ & $<.001$ & $\begin{array}{l}2.439(1.696- \\
3.506)\end{array}$ & 0.018 \\
\hline & \multicolumn{5}{|l|}{$\begin{array}{l}\text { Overall stage (8th } \\
\text { edition) }\end{array}$} \\
\hline LRFS & III + IV vs. I+ II & $\begin{array}{l}1.844(1.377- \\
2.471)\end{array}$ & $<.001$ & $\begin{array}{l}5.792(2.303- \\
14.565)\end{array}$ & 0.014 \\
\hline & \multicolumn{5}{|l|}{ Post-EBV (copies/mL) } \\
\hline & $\geq 2500$ vs. $<2500$ & $\begin{array}{l}1.883(1.404- \\
2.525)\end{array}$ & $<.001$ & $\begin{array}{l}5.363(2.201- \\
7.312)\end{array}$ & 0.008 \\
\hline & \multicolumn{5}{|l|}{ T category } \\
\hline & T3-4 vs. T1-2 & $\begin{array}{l}1.343(1.057- \\
1.707)\end{array}$ & 0.016 & & \\
\hline & \multicolumn{5}{|l|}{$\mathrm{N}$ category } \\
\hline & N2--3 vs. N0-1 & $\begin{array}{l}5.793(3.691- \\
9.092)\end{array}$ & $<.001$ & $\begin{array}{l}3.894(2.346- \\
6.464)\end{array}$ & $\begin{array}{l}< \\
0.001\end{array}$ \\
\hline PFS & \multicolumn{5}{|l|}{$\begin{array}{l}\text { Overall stage (8th } \\
\text { edition) }\end{array}$} \\
\hline & III + IV vs. I+ II & $\begin{array}{l}3.662(1.934- \\
6.935)\end{array}$ & $<.001$ & $\begin{array}{l}2.849(1.161- \\
6.994)\end{array}$ & 0.022 \\
\hline & \multicolumn{5}{|l|}{ Post-EBV (copies/mL) } \\
\hline & $\geq 2500$ vs. $<2500$ & $\begin{array}{l}2.375(1.427- \\
3.954)\end{array}$ & 0.001 & $\begin{array}{l}1.940(1.153- \\
3.264)\end{array}$ & 0.013 \\
\hline
\end{tabular}

\section{EBV DNA kinetics and survival}

The 5-year OS rates for patients with sustained remission was $93.8 \%$, which was significantly improved compared with that of the recurrence (47.6\%) and metastasis (26.9\%) groups (Fig. 3), with a significant 
difference observed between the three groups (recurrence vs. sustained remission HR: $12.227 ; 95 \% \mathrm{Cl}$ : 6.568-22.760; $P<0.001$, metastasis vs. sustained remission HR: 15.842; 95\% Cl: 10.494-23.916; $P<$ $0.001)$.

According to baseline EBV DNA load and EBV kinetics, patients were further divided into three groups as follows: (1) continuously normal group: patients whose baseline EBV DNA normal and never elevated, 679 cases; (2) ever-elevated group: patients whose EBV DNA ever-elevated regardless time points, 97 cases; (3) continuously elevated group: patients whose baseline EBV DNA was elevated and never normalized, 124 cases. The 5 -year OS rates in the three groups were $93.2 \%, 76.2 \%$ and $59.9 \%$, respectively (Fig. 4A); DMFS rates were 94.4\%, 84.3\% and 59.9\%, respectively (Fig. 4B); LRFS rates were $98.1 \%, 91.5 \%$ and $95.8 \%$, respectively (Fig. 4C); and PFS rates were $94.8 \%, 83.9 \%$ and $73.7 \%$, respectively (Fig. 4D). There were significant differences among the three groups in OS (HR: 2.542, 95\% Cl:2.077-3.111, $P<$ 0.001), DMFS (HR:2.970, 95\%Cl: 2.392-3.687, $P<0.001)$, LRFS (HR: $1.699,95 \% \mathrm{Cl}: 1.072-2.692, P=$ 0.013 ), and PFS (HR: $2.535,95 \% \mathrm{Cl}: 1.987-3.233, P<0.001)$.

\section{Landmark Analyses}

Of 900 patients in the whole group, a total of 887 patients were alive and had follow-up for at least 12 months and therefore they were included in the 12-month landmark analysis for survival (Fig. 5A). The 5 -year OS of the 732 patients whose EBV DNA load sustained remission was $91.3 \%$, and the elevated group was $74.4 \%$ (HR: $3.182,95 \% \mathrm{Cl}: 2.114-4.788, P<0.001)$.

Besides, a total of 854 patients were alive or had follow-up for at least 24 months and therefore were included in the 24-month landmark analysis for survival (Fig. 5B). The 5-year OS of the 746 patients whose EBV DNA load sustained remission was $95.0 \%$, and the elevated group was $62.9 \%$ (HR: $9.619,95 \%$ Cl: 6.027-15.353, $P<0.001)$.

\section{Discussion}

Many non-specific markers have been demonstrated to play important roles in predicting tumor progression and prognosis. EBV DNA load is the most representative marker in NPC [16] and is widely used in screening, monitoring, and prediction of relapse in non-metastatic NPC [17]. Circulating EBV DNA concentrations correlate positively with disease stage as well as exhibiting prognostic importance in NPC [11]. Based on the great variety of published studies [12, 18, 19], EBV DNA concentrations during treatment and plasma EBV DNA clearance rates have been identified as emerging biomarkers of survival $[19,20]$. Furthermore, some studies have stratified the role of EBV DNA in predicting metastasis and recurrence of NPC [17]. A prospective study demonstrated that EBV DNA load was a predictor of distant metastasis [21]. In patients with recurrent NPC requiring salvage nasopharyngectomy, preoperative plasma EBV DNA identifies patients at high-risk of subsequent distant failure after surgery. Serial measurements of plasma EBV DNA after surgery, especially for those with high preoperative levels, is crucial to allow early detection of local of distant failure [22]. 
In contrast, there are few reports describing the role of post-treatment EBV DNA in NPC, especially indepth analysis of the dynamic changes and common variation tendencies. Li et al. [23] revealed that $6.5 \%$ (19/292) of patients with undetectable EBV DNA and 57.0\% (53/93) of patient with detectable EBV DNA during post-treatment follow-up experienced tumor recurrence. Plasma EBV DNA level during posttreatment follow-up is a good marker for predicting distant metastasis, but not locoregional recurrence.

The dynamic changes of EBV DNA in the recurrence and metastasis groups can be summarized by the common rule that the EBV DNA decreased rapidly at the end of treatment, approaching 0 copies $/ \mathrm{mL}$, although the low concentration was maintained for a short time (approximately 3 months). After 3 months of treatment, the EBV DNA increased gradually until the peak value was reached at the point of clinical diagnosis of metastasis or recurrence. In the recurrence group, EBV DNA increased slowly during 1-2 years post-treatment, and increased rapidly from 2 years, with no obvious peak reached. In the metastasis group, EBV DNA began to rise after 3 months, which was earlier than that observed in the recurrence group. In contrast to the recurrence group, peak EBV DNA levels were reached in metastasis group. The dynamic changes in EBV DNA load coincided with the median time of metastasis at 15 months. There were significant differences in EBV DNA kinetics between the sustained remission and recurrence groups and between the sustained remission and metastasis groups, but not between the recurrence and metastasis groups.

The mechanism underlying the impact of the dynamic changes in EBV DNA load on NPC recurrence and metastasis remains to be clarified and no risk classification has been effectively demonstrated. Thus, in this study, we stratified the kinetic changes in EBV DNA loads at 0 months, 3 months, 1 year, 2 years and 3 years after treatment, and revealed that different combinations of post-treatment EBV DNA groups may better predict OS, DMFS, LRFS and PFS in NPC patients. Furthermore, we characterized the patterns of dynamic changes in EBV DNA load in the sustained remission, recurrence and metastasis groups.

Even if the pre-treatment EBV DNA load is higher than the cutoff value of $(4,000$ copies $/ \mathrm{mL}$, the prognosis remains good if the fluctuation range of EBV DNA in patients after treatment is lower than the cutoff value. However, the prognosis of patients with EBV DNA loads that continue to exceed the cutoff value after treatment is poor, and the probability of clinical events is high. In such cases, pre-treatment EBV DNA load has no prognostic value. Thus, the influence of EBV DNA on survival after treatment is stronger than that before treatment.

Additionally, there were significant difference in OS by 12 and 24-month landmark analyses in patients with different EBV DNA load groups. Thus, analysis of this marker should be added to the imaging examination to provide a complete post-treatment follow-up.

\section{Conclusions}

Our results showed that in patients with NPC, elevated EBV DNA during follow-up can reflect the possibility of recurrence and metastasis, as well as an unfavorable prognosis. Also, there were significant difference in OS by landmark analysis. These findings indirectly verify the significance of EBV DNA 
during the follow-up time in NPC. We believe that a better understanding of EBV DNA kinetics would be of paramount importance for the rational use of this new class of tumor markers. Thus, we can use EBV DNA load to intensify the examination or treatment regimens accordingly.

\section{Declarations}

Ethics approval and Informed consent: All procedures performed in studies involving human participants were in accordance with the ethical standards of the institutional and/or national research committee and with the 1964 Helsinki declaration and its later amendments or comparable ethical standards. Informed consent of therapy were obtained from all individual participants included in the study. This was a retrospective study so the consent to participate was exempted.

Conflict of interest: The authors declare that they have no competing interests.

Funding: The study was supported by the National Natural Science Foundation of China [grant number 81903037]. The funding agency had no role in the study design, data collection and analysis, decision to publish, or preparation of the manuscript.

Authors contributions: Yong Chen, Lixia Lu and Yan Wang designed this study; Sha-sha He and Mei-yan Zhu collected the clinical data; Yu-feng Ren and Cheng-tao Wang performed statistical analyses; Yong Chen gave critical comments and suggestions; Sha-sha He and Yun-ying Yang drafted the manuscript; all authors approved the final version of the manuscript.

\section{Availability of data and materials}

All data generated or analyzed during this study would be supported if needed.

\section{References}

1. Wee JT, Ha TC, Loong SL, Qian CN. Is nasopharyngeal cancer really a "Cantonese cancer". Chinese journal of cancer. 2010;29(5):517-26.

2. Chua MLK, Wee JTS, Hui EP, Chan ATC. Nasopharyngeal carcinoma. Lancet. 2016;387(10022):1012-24.

3. Pfister DG, Ang KK, Brizel DM, Burtness BA, Busse PM, Caudell JJ, Cmelak AJ, Colevas AD, Dunphy F, Eisele DW, et al. Head and neck cancers, version 2.2013. Featured updates to the NCCN guidelines. Journal of the National Comprehensive Cancer Network: JNCCN. 2013;11(8):917-23.

4. Chan AT. Nasopharyngeal carcinoma. Annals of oncology: official journal of the European Society for Medical Oncology. 2010;21(Suppl 7):vii308-312.

5. Guan Y, Liu S, Wang HY, Guo Y, Xiao WW, Chen CY, Zhao C, Lu TX, Han F. Long-term outcomes of a phase II randomized controlled trial comparing intensity-modulated radiotherapy with or without 
weekly cisplatin for the treatment of locally recurrent nasopharyngeal carcinoma. Chinese journal of cancer. 2016;35:20.

6. Leung SF, Lo YM, Chan AT, To KF, To E, Chan LY, Zee B, Huang DP, Johnson PJ. Disparity of sensitivities in detection of radiation-naive and postirradiation recurrent nasopharyngeal carcinoma of the undifferentiated type by quantitative analysis of circulating Epstein-Barr virus DNA1,2. Clinical cancer research: an official journal of the American Association for Cancer Research. 2003;9(9):3431-4.

7. Weng J, Wei J, Si J, Qin Y, Li M, Liu F, Si Y, Su J. Clinical outcomes of residual or recurrent nasopharyngeal carcinoma treated with endoscopic nasopharyngectomy plus chemoradiotherapy or with chemoradiotherapy alone: a retrospective study. PeerJ. 2017;5:e3912.

8. Chan WK, Kwong DL, Yeung DW, Huang B, Khong PL. Prognostic impact of standardized uptake value of F-18 FDG PET/CT in nasopharyngeal carcinoma. Clinical nuclear medicine. 2011;36(11):1007-11.

9. Yen RF, Hung RL, Pan MH, Wang YH, Huang KM, Lui LT, Kao CH. 18-fluoro-2-deoxyglucose positron emission tomography in detecting residual/recurrent nasopharyngeal carcinomas and comparison with magnetic resonance imaging. Cancer. 2003;98(2):283-7.

10. He SS, Wang Y, Bao Y, Cai XY, Yang XL, Chen DM, Chen Y, Lu LX. Dynamic changes in plasma Epstein-Barr virus DNA load during treatment have prognostic value in nasopharyngeal carcinoma: a retrospective study. Cancer medicine. 2018;7(4):1110-7.

11. Lo YM. Quantitative analysis of Epstein-Barr virus DNA in plasma and serum: applications to tumor detection and monitoring. Ann N Y Acad Sci. 2001;945:68-72.

12. Wang WY, Twu CW, Chen HH, Jan JS, Jiang RS, Chao JY, Liang KL, Chen KW, Wu CT, Lin JC. Plasma EBV DNA clearance rate as a novel prognostic marker for metastatic/recurrent nasopharyngeal carcinoma. Clinical cancer research: an official journal of the American Association for Cancer Research. 2010;16(3):1016-24.

13. Lam JW, Chan JY, Ho WK, Tsang RK. Use of transoral nasopharyngeal brush biopsy for Epstein-Barr virus DNA detection of local recurrence of nasopharyngeal carcinoma after radiotherapy. Head Neck. 2016;38(Suppl 1):E1301-4.

14. Lo YM, Chan LY, Chan AT, Leung SF, Lo KW, Zhang J, Lee JC, Hjelm NM, Johnson PJ, Huang DP. Quantitative and temporal correlation between circulating cell-free Epstein-Barr virus DNA and tumor recurrence in nasopharyngeal carcinoma. Cancer research. 1999;59(21):5452-5.

15. Li YH, Shao JY, Zhao MQ, Gao HY, Li LR, Guan ZZ, Zeng YX. [Quantitative analysis of plasma Epstein-Barr virus (EBV) DNA for monitoring of recurrence and metastasis in nasopharyngeal carcinoma patients after radiotherapy]. Ai zheng $=$ Aizheng $=$ Chinese journal of cancer. 2003;22(6):645-8.

16. Lin JC, Wang WY, Chen KY, Wei YH, Liang WM, Jan JS, Jiang RS. Quantification of plasma EpsteinBarr virus DNA in patients with advanced nasopharyngeal carcinoma. N Engl J Med. 2004;350(24):2461-70. 
17. An X, Wang FH, Ding PR, Deng L, Jiang WQ, Zhang L, Shao JY, Li YH. Plasma Epstein-Barr virus DNA level strongly predicts survival in metastatic/recurrent nasopharyngeal carcinoma treated with palliative chemotherapy. Cancer. 2011;117(16):3750-7.

18. Leung SF, Zee B, Ma BB, Hui EP, Mo F, Lai M, Chan KC, Chan LY, Kwan WH, Lo YM, et al. Plasma Epstein-Barr viral deoxyribonucleic acid quantitation complements tumor-node-metastasis staging prognostication in nasopharyngeal carcinoma. Journal of clinical oncology: official journal of the American Society of Clinical Oncology. 2006;24(34):5414-8.

19. Lin JC, Chen KY, Wang WY, Jan JS, Liang WM, Tsai CS, Wei YH. Detection of Epstein-Barr virus DNA in the peripheral-blood cells of patients with nasopharyngeal carcinoma: relationship to distant metastasis and survival. Journal of clinical oncology: official journal of the American Society of Clinical Oncology. 2001;19(10):2607-15.

20. To EW, Chan KC, Leung SF, Chan LY, To KF, Chan AT, Johnson PJ, Lo YM. Rapid clearance of plasma Epstein-Barr virus DNA after surgical treatment of nasopharyngeal carcinoma. Clinical cancer research: an official journal of the American Association for Cancer Research. 2003;9(9):3254-9.

21. Li SW, Wang H, Xiang YQ, Zhang HB, Lv X, Xia WX, Zeng MS, Mai HQ, Hong MH, Guo X. Prospective study of prognostic value of Raf kinase inhibitory protein and pretreatment plasma Epstein-Barr virus DNA for distant metastasis in locoregionally advanced nasopharyngeal carcinoma. Head Neck. 2013;35(4):579-91.

22. Chan JY, Wong ST. The role of plasma Epstein-Barr virus DNA in the management of recurrent nasopharyngeal carcinoma. Laryngoscope. 2014;124(1):126-30.

23. Li WF, Zhang Y, Huang XB, Du XJ, Tang LL, Chen L, Peng H, Guo R, Sun Y, Ma J. Prognostic value of plasma Epstein-Barr virus DNA level during posttreatment follow-up in the patients with nasopharyngeal carcinoma having undergone intensity-modulated radiotherapy. Chinese journal of cancer. 2017;36(1):87.

\section{Figures}




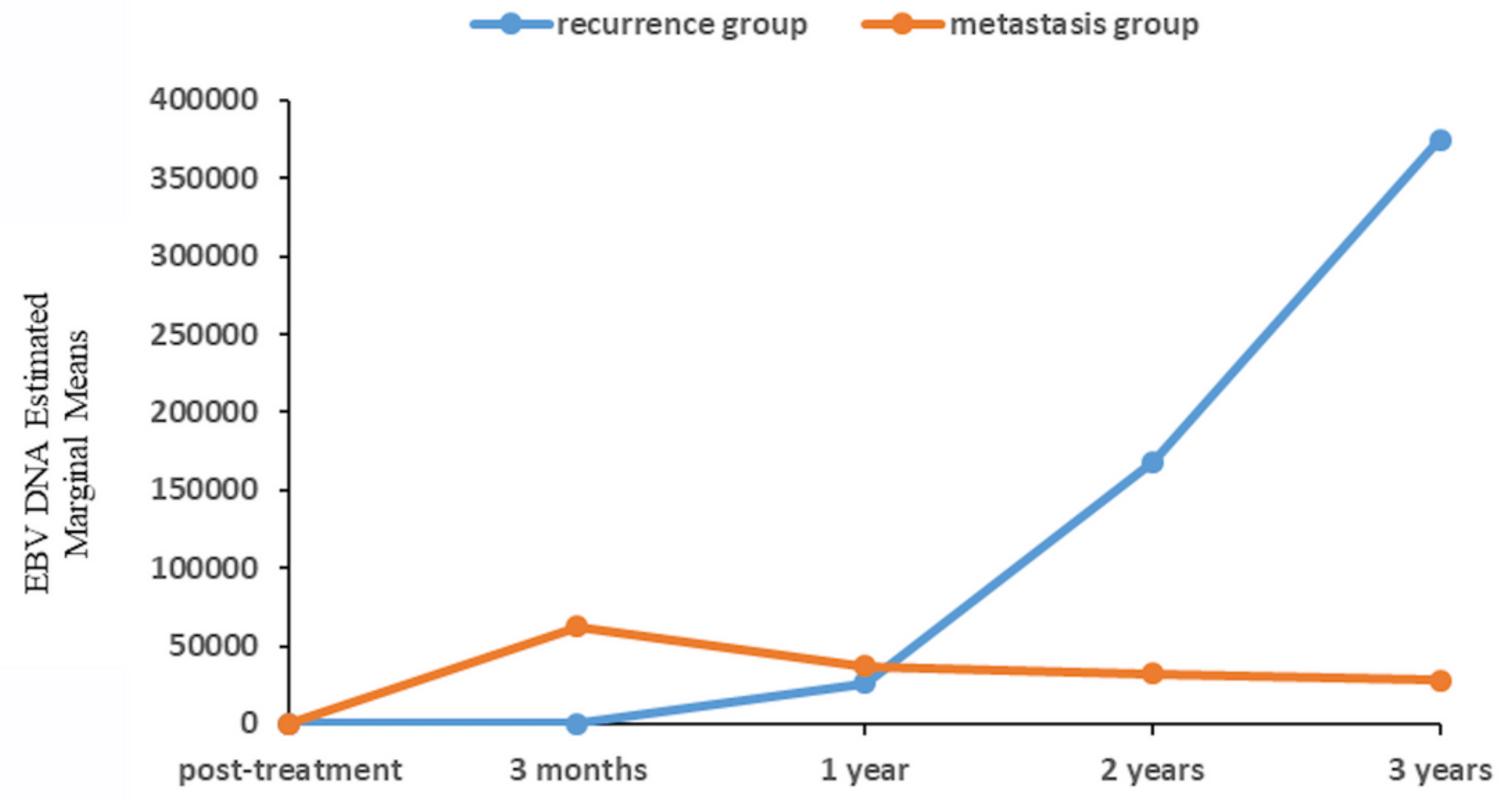

Figure 1

Changes patterns of EBV DNA in the recurrence and metastasis groups during the follow-up. 

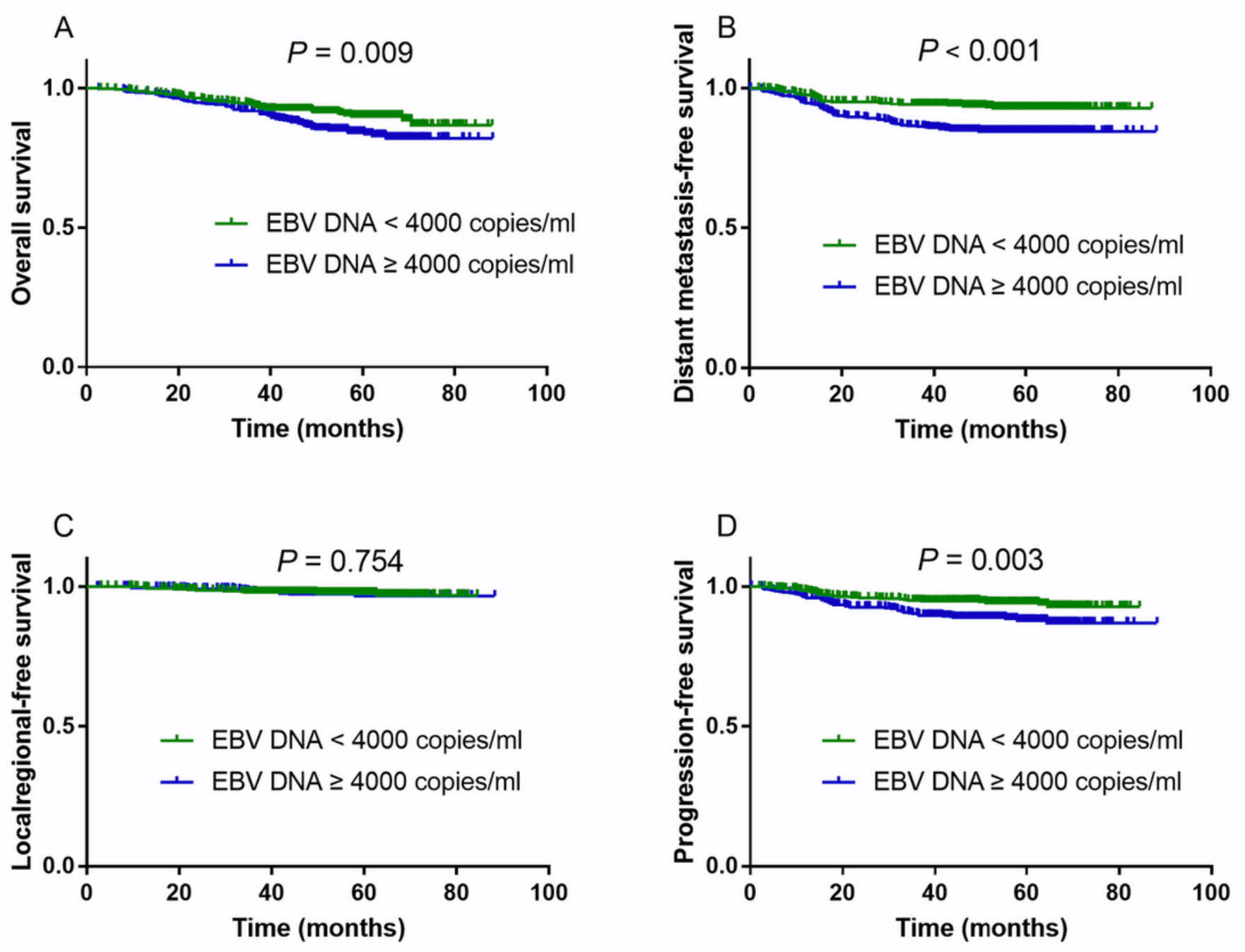

Figure 2

Plasma EBV DNA before treatment higher than 4,000 copies $/ \mathrm{mL}$ is associated with poorer survival outcomes. Kaplan-Meier overall survival (A), distant metastasis-free survival (B), local regional-free survival (C) and progression-free survival (D). 


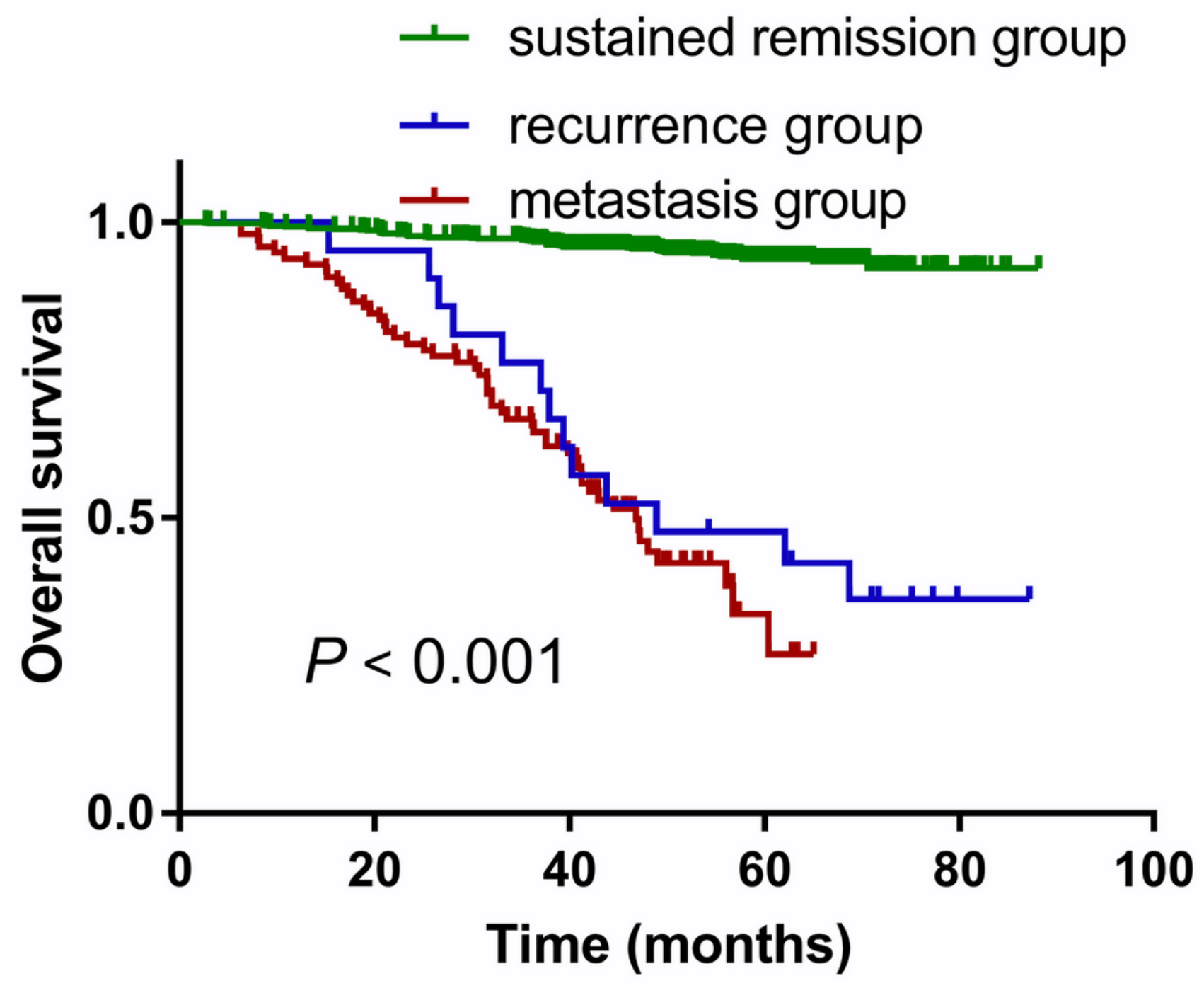

Figure 3

Plasma EBV DNA in the metastasis group and recurrence are associated with poorer overall survival. 

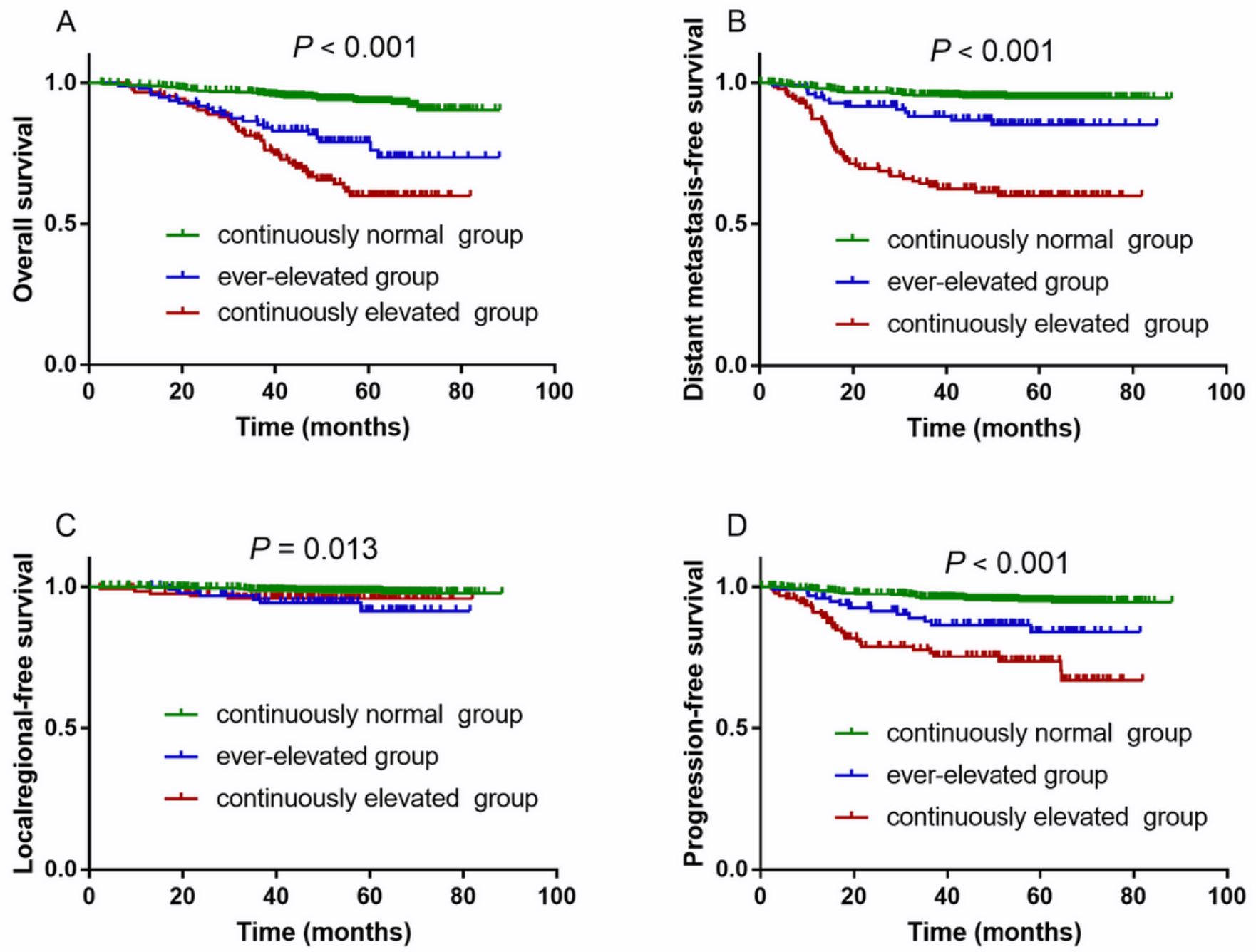

\section{Figure 4}

Survival outcome differences in the EBV DNA continuously normal, ever-elevated and continuously elevated groups. Kaplan-Meier overall survival (A), distant metastasis-free survival (B), local regional-free survival (C) and progression-free survival (D). 

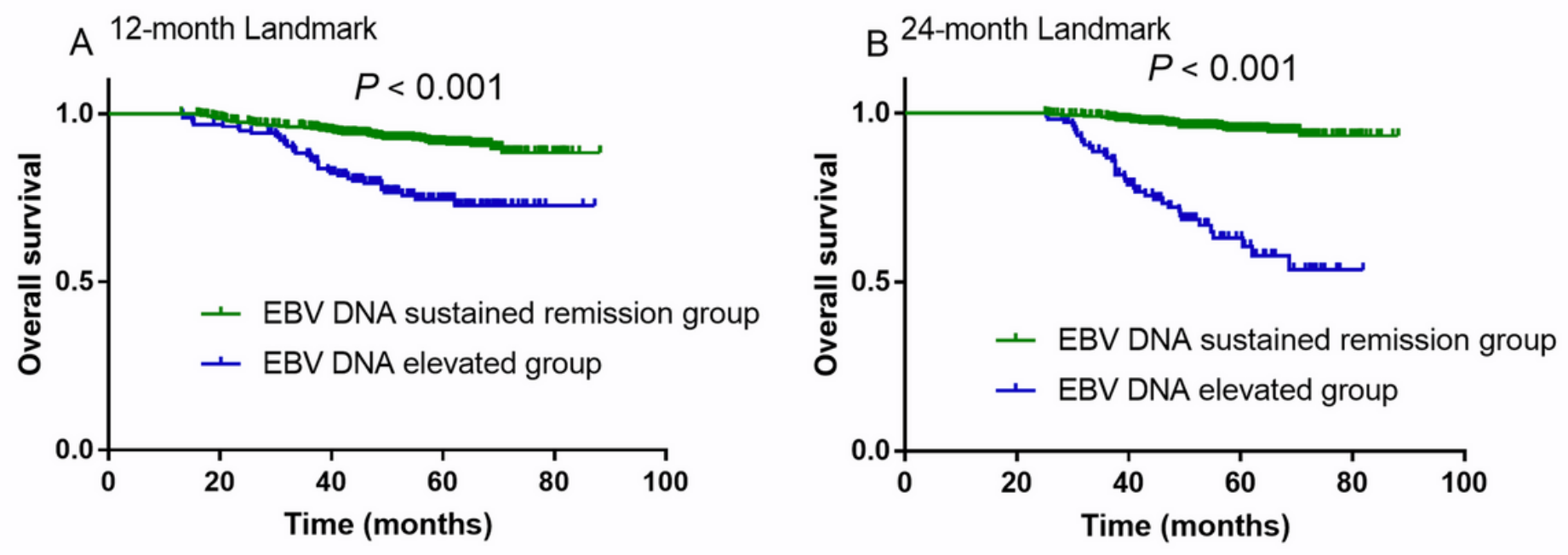

Figure 5

Survival outcome differences in the EBV DNA sustained remission and elevated groups during follow-up. 12-month landmark (A), 24-month landmark (B). 